\title{
Improving Maternal, Neonatal and Child Health through Manoshi Project in Bangladesh
}

\author{
Shamima Nasrin ${ }^{1, *}$, Faisal Ahammed ${ }^{2}$ \\ ${ }^{1}$ School of Health Sciences, Flinders University, Australia \\ ${ }^{2}$ School of Natural \& Built Environments, University of South Australia, Australia
}

Copyright $\mathrm{O} 2016$ by authors, all rights reserved. Authors agree that this article remains permanently open access under the terms of the Creative Commons Attribution License 4.0 International License

\begin{abstract}
This article presents the description of changes in terms of maternal, neonatal and child health due to the initiatives of Manoshi Project by Bangladesh Rural Advancement Committee (BRAC). Analysis of changes is also highlighted here. BRAC started the Manoshi Project to bring skilled care into the informal settlement of six major cities in Bangladesh in 2007. Three core methods including social mapping, census tacking and community engagement were adopted to achieve the aims of Manoshi project. This project has successfully reached to the most vulnerable women and children with very low cost and minimum infrastructure. The Manoshi Project has empowered the community through social mobilization, advocacy and communication.
\end{abstract}

Keywords Maternal Health, Neonatal Health, Child Health, Improvement, Manoshi Project

\section{Introduction}

Now-a-days global urbanization has become an emerging issue. Bangladesh and other Asian countries have experienced rapid urban growth in the recent decades [1]. Infrastructure and public services are unable to keep up with this growth. So, urban poverty and equality are also increasing day by day. All these affect health profile especially maternal and child health [1].

Bangladesh has witnessed remarkable progress in health status over the last few decades [2]. Some examples are improving access to maternity care service and improving outcomes of maternal, neonatal and child health in the urban slums of Bangladesh. This change has become through the Manoshi Project. BRAC, one of the biggest NGOs in Bangladesh, started the Manoshi Project in 2007 to bring skilled care into the informal settlement of six major cities in Bangladesh [3]. It is a community based interventions where essential care program model of BRAC are adapted. BRAC's proposed approach and child health is unique because along with community based health interventions, it also strengthens health systems. The components of Manoshi Project are capacity development of community health worker and birth attendants who provide antenatal care (ANC) safe delivery and post-natal care (PNC), neonatal and child health care, health service provision for pregnant lactating women, neonates and under five children, timely referral to quality health facilities, community empowerment through the development of women's groups and linkage with state and local government, community people and NGOs [3]. The aim of this program is to reduce the morbidity and mortality of the mothers, newborns and children in urban slums of Bangladesh through development and delivery of an integrated, community based package of essential health services. This program seeks to create demand for services in the community through increasing knowledge building capacity of the service provider and develop effective return linkage for emergency obstetric care [4].

People living in urban slums face much greater challenge to improve their health from other parts of the country [3]. Access to health care and health status is quite poor in informal urban settlements across Bangladesh. Despite living in relatively close proximity to health service, the urban poor use these services at very low rate [2]. At the time of the projects' inspection in 2007, this population had high maternal and neonatal mortality [5]. A 2008 service population survey revealed a maternal mortality ratio of 294 per 100,000 live births and a neonatal mortality rate of 43 per 1000 live births in 2008 [6]. Moran et al. [7] reported that a great majority of women (about $86 \%$ ) gave birth at home and only a quarter received antenatal and post-natal care. After the initiating of Manoshi Project, significant improvement was observed. For example, 13\% women now gave birth at home, the maternal mortality ratio fallen by $56 \%$ to 130 per 100,000 live births in 2013 [6]. According to Maternal Death Audit Report [8], the neonatal mortality rate fallen by $60 \%$ to $17 \%$ per 1000 live births in 2013 compared to a baseline rate in 2008 of $43 \%$ per 1000 live births [6]. The proportions of pregnant women in Manoshi's target areas receiving four antenatal visits increased from $27 \%$ to $78 \%$ over five years. 
Home birth without any skilled attendant decreased from $86 \%$ to $16 \%$ over a five year period. Postnatal care visits within 24 hours of birth increased from $6 \%$ to $99 \%$ in 5 years. Early initiation of breast feeding within the first hour of birth increased $50 \%$ to $71 \%$ in four years [9]. Exclusive breast feeding during the first six months of life increased from $43 \%$ to $65 \%$ over a five year period [6].

\section{Methodology}

This study was conducted through analysing secondary data. Relevant journal and conference papers, technical and government reports were collected, screened and analysed properly. Personal communication to relevant person was also performed to understand about Manoshi project. Field visit to Tangail, Bangladesh was performed during the period of November and December 2015. Activities of Manoshi project was practically observed and noted for analysis during the field visit.

\section{Success of Manoshi Project}

Three core methods were adopted to achieve the success of Manoshi project. These are social mapping, census tacking and community engagement.

\section{Social Mapping}

It is the process of creating a map of the community in collaboration with the community. To undertake social mapping, many levels of program staff, identified key informants, created a household lists, other community structures in a systematic manner, consulted with households to verify map accuracy and created maps at the program level. These steps make staff familiarized with community and facilities the program which are important for successful implementation [5].

\section{Census Tacking}

BRAC's methods to complete a census included selecting surveyors and planning for the survey in collaboration with the Maternal Neonatal and Child Health $(\mathrm{MNCH})$ committee training surveyors along with the program staff and carrying out the census with overnight from the monitoring unit. This helps BRAC to acquire proper data collection, identify community needs, engage them and allocate resources properly.

\section{Community Engagement}

BRAC engages community by differentiate approach include forming $\mathrm{MNCH}$ committee and women's support group, mass marketing, social mobilization, responding to communities feedback, integrating program activities with local community structure. All these increase the trust and acceptance of people [5].

The Manoshi Project is structured with a dual Cadre
Network of Community Health Workers (CHWs) called Shasho Shebika and Shasho Kormi. CHWs are the backbone of Manoshi Project who is the first level of BRAC's community health workers. Using trained CHWs and urban birth attendants at delivery centres through the slums, the Manoshi Project successfully reaches the most vulnerable women and children with very low cost and minimum infrastructure. In order to improve the maternal neonatal and child health, Manoshi Project has initiated several strategies including:

- CHWs identify pregnant women and offer ANC and PNC. They also encourage to give birth at BRAC's birth centre, where high quality health facilities are available.

- ANC includes physical examination, education on health practice and hygiene, counselling on nutrition motivation for tetanus immunization, iron folic acid supplementation, education on danger sign and birth preparedness.

- The midwives of Manoshi Project assist at deliveries, control postpartum bleeding with misoprostol, manage birth asphyxia, weight newborn and teach kangaroo mother care for low birth weight babies.

- $\quad$ PNC visits are scheduled for days 1, 3, 7, 21 and 28 and include health education on new born care, exclusive breast feeding, maternal nutrition and hygiene, immunization and postpartum family planning.

- CHWs keep track of all birth records, offer essential newborn care, manage neonatal complications, for under live; they promote healthy feeding practice, monitor growth, manage diarrhoea, and respiratory inspection.

- The Manoshi Project relies on committee of local stakeholders who observe and monitor health actions.

- The midwives of this project conduct normal delivery at birth centres of BRAC. When complications arise, referral systems are also available with local community networks. There is a partnership with private and public hospital to manage more complicated case [8].

\section{Analysis of Change}

To improve maternal neonatal and child health in the urban slums of Bangladesh, empowerment plays an important role. The Manoshi Project is trying the community to empower through social mobilization, advocacy and communication. In social mobilization, BRAC's Program Organizers discuss current best practices of maternal, neonatal and child health to different groups of people carefully. They also aware people about ill effects of bad practice, for example, delivery in complication, irrational drug use etc. [3]. BRAC facilitates social mobilization through building community and stakeholder capacity. 
BRAC's Program Organizers sensitize state and local government officials, political leaders, health professionals and other stakeholders. MNCH committee also formed to monitor issues and outcomes. With the help of local NGOs and government, they also advocate to change the community. Health education and promotion activities are also provided within different groups of people. Awareness of early signs of labour, birthing place, newborn care, neonatal and children care hygiene behaviour, pneumonia etc. are raised through media and forum, small group discussion. Some communication strategies such as popular theatre, folk songs are also used. Radio, television are important for mass campaign. Stickers, leaflets, posters etc. are used to disseminate important messages [3].

Five elements of community empowerment - capacity building, human rights, organizational sustainability, institutional accountability, contribution enabling environment are the foundation of maternal health program [3]. Several gaps regarding empowerment are observed in this Manoshi Project. A challenge in building capacity in a scaled up interventions is related to issues of quality. This $\mathrm{MNCH}$ program, the recruitment and training of community health workers are conducted side by side; usually CHWs immediately start the work right after completion of the training. Standards are influenced by experience, competency and supervisory skills. So, quality of this program may fluctuate upon these factors [3]. Besides, health workers remuneration is low that leads to limited motivation and poor quality of care [8]. Ahmed et al. [4] revealed that some gaps in the $\mathrm{MNCH}$ program on Manoshi Project in urban slums of Bangladesh. They reported the capacity to provide rational and quality services is questionable and community has sacrificed knowledge of $\mathrm{MNCH}$ care and service. Social support network for health is also poor and referral linkage to higher facilities is adequate, fragmentary and disorganized [4]. They also reported that many members of the committee do not regularly attend in the meeting and unware of their responsibilities. The roles of committee are insufficiently defined and not clear to the member. Another challenge is that about sustainability. The portion of CHW drop out is also high. Their incentive package is not as good as market price. So they would like to enter into new jobs. Behaviour Change Communication (BCC) is the important strategy to empower these services of Manoshi Project, however the cost of BCC intervention is very high. Therefore, the sustainability of this program is questioned.

There are many barriers of $\mathrm{MNCH}$ program in urban slums of Bangladesh. Socio-economic factors are one of the major barriers of empowerment [10]. Poverty, overcrowded conditions, poor housing, lack of knowledge, social exclusion, economic vulnerability etc. are the major threats of development [11].

Education is strongly associated with health inequalities, because it provides a main route out of poverty and empowers people - financially, psychologically and politically $[12 ; 13]$. Socially disadvantaged, marginalized groups or slum people face many barriers to achieve education, for example, geographical location of school, financial problem etc. [6]. Employment, availability, salaries, working conditions affect health equity through the material and social empowerment that they convey. Financial insecurity is the most determined among urban dwellers of Bangladesh and they experienced unemployment, underemployment, temporary employment, lack of social security benefits etc. [11]. Social exclusion of urban slums of Bangladesh is defined as a social groups residing in specific geographical areas that are excluded from access to resources and opportunities offered by city [14].

Urban slum people are highly mobile, they usually migrate within the slum to other slums or back to home or village. So, community engagement is difficult for the BRAC staffs because of their highly transient nature [5]. Social capital and social network have important affect to empowerment. Socially disadvantage people often rely on their invisible informal social capital and social network to counteract adverse living conditions [11].

Urban slum people have many cultural beliefs and traditions about child birth which affect the maternal and child health [15]. Ahmed et al. [4] reported that slum dwellers have strong network for social and economic problems but not as effective networks for health related problems. Lack of social supports is another important barrier of empowerment.

Gender inequality is another barrier for women empowerment in developing countries. Girls usually get less education than boys, there is less investment in women's health than in men, legal rights of women in the economy and marriage are minimum in developing countries [16].

Community health workers are the main facilitators for empowerment. Along with identifying pregnancy, bringing them delivery centres, accompany pregnant women during their delivery and providing new born care, they also disseminate health message. They play an important role in social network which is the main way to empower for the poor and marginalized group [17].

Female community health workers are trained to empower the community by raising awareness and providing maternal services. Frequent contact with mothers at domiciliary level is noted. They have a strong connection with the community. By creating demand and providing service, the community health workers are also equally empowered. Behaviour Change Communication (BCC) intervention act facilitator for empowerment. The BCC component aims to raise awareness and create behaviour change.

Laverack [18] identified nine domains for community empowerment those are useful strategies for improving maternal, neonatal and child health.

\section{Participation}

Participation is necessary for empowerment. Interpersonal trust and trust in public institute are increased if individuals 
can participate with same circumstances of people. Participating with groups, people can define, analyse and finalize regarding issues of child birth. Social network and social support are also increased by participation. People can cope with stressful events by sharing problems which can lead to empowerment [19]. Everson et al. [20] reported that there is strong linkage with psychological empowerment and health.

\section{Community Based Organization}

Community based organizations such as youth groups, committees, cooperative and sports associations where people come to socialize and to address their boarder concerns. This is a good opportunity to broad their knowledge and skills that can lead to empowerment.

\section{Local Leadership}

Leaders require a strong participation base who can move and direct to the community. The selection of appropriate leadership can be seen as pluralistic approach in the community where there is interplay between the position and leaders [21].

\section{Resource Mobilization}

Individuals, groups and communities have the ability to raise resource from within. The ability of the community to mobilize resource from within and to negotiate resources from beyond is an indication of a developed organization ability. A long with resource mobilization, improved literacy, education are also necessary for good health outcome in developing countries [2].

\section{Asking Why}

It means the ability of community to assess critically the contextual issues of their powerlessness and poor health. Critical thinking and critical awareness are the main approaches. The critical thinking people are encouraged to discuss and share experience, problems openly. Then the facilitators set problems for women to explore the root causes of poverty, mortality and morbidity.

\section{Assessment of Problems}

Although for improving health outcome, assessment of problem is not the first step, the program could be set accordingly what the members of community want. With the tackling community problems, many personnel, social and economic factors may be covered.

\section{Links with Other People and Organizations}

To address community health needs, links with other people and organization are important parts. It is based on mutual interest. The development of partnership is an important step towards empowerment and can also lead to an improvement in health outcome by pooling limited resources and by taking collective actions.

Role of Outside Agents and Program
Population health related programs are traditionally professionally led. The practitioners or their agency mainly choose and control method, design and evacuate. The outside agent must sense of control of the issues to the community [18].

Along with these Laverack's domains, there are some factors which can contribute for Manoshi Project's successful implementation. For example, birth centres will be culturally appropriate where women can easily move for care in a respectful way. $\mathrm{MNH}$ services should be set up along the continuum of care; having evidence based protocols for all aspects of care is important to maintain and establish quality of care.

Continual monitoring and evaluation is crucial for improving service delivery and outcomes [8]. The number of health workers have to be increased. Their drop out is very high. Their performance based income is very low compare to their workload [17]. So, fixed income is needed for their motivation and poor performance.

\section{Conclusions}

Urban slum population is socially, economically, politically, environmentally and psychologically disadvantaged [13]. Due to their low level of health literacy and autonomy, they are less likely to take part in health and health care service. So concerned efforts are needed to educate and empower the urban poor to enable them to take informal decision and actions for promoting and preserving their health. Community health workers and volunteers play an important role in health education and empowerment of the urban poor, strong community organizations and social network could be established through the supports of NGOs and related government organizations [13].

\section{REFERENCES}

[1] NIPROT (2006), 'Bangladesh urban health survey', ICDDRB, Bangladesh.

[2] Pokhrel, S. \& Sauerborn, R. (2004), 'Household decision making on child health care in developing countries: the case of Nepal', Health Policy Planning, vol. 19, pp: 218-233.

[3] Afsana, K., Alam, A., Chowdhury, M. Rhode, J. \& Ahmed, F. (2009), 'A program for improving maternal, neonatal and child health in the urban slums of Bangladesh', Manoshi Working Paper Series, BRAC NGO, Bangladesh.

[4] Ahmed, S. M., Hossain, A., Khan, M. A., Mridha, M. K., Alam, A., Choudhury, N., Sharmin, T. Afsana, K. \& Bhuiya, A. (2010), 'Using formative research to develop $\mathrm{MNCH}$ program in urban slums in Bangladesh: experiences from Manoshi, BRAC', BMC Public Health, vol. 10, pp: 1-8.

[5] Roy, T., Marcil, L., Chowdhury, R. H., Afsana, K. \& Perry, H. (2011), 'The BRAC Manoshi approach' The BRAC, Bangladesh. 
[6] Sarker, B. K., Ahmed, S., Islam, N. \& Khan, J. A. M. (2013), 'Cost of behaviour change communication channels of Manoshi - a maternal, neonatal and child health $(\mathrm{MNCH})$ program in urban slums of Dhaka, Bangladesh', Cost Effectiveness and Resource Allocation, vol. 28, no. 11, pp: $1-10$.

[7] Moran, A. C., Choudhury, N., Khan, U. Z., Wahed, T., Rashid, S. F. \& Alam, M. A. (2009), 'Newborn cares practices among slum dwellers in Dhaka, Bangladesh: a quantitative and qualitative exploratory study', BMC Pregnancy Childbirth, vol. 9, pp: 1-8.

[8] Maternal Health Task Force (2014), 'The Manoshi Project', School of Public Health, Harvard University.

[9] Alam, K., Tasneem, S. \& Huq, M. (2014), 'Reservation wage of female volunteer community health workers in Dhaka urban slums: a bidding games approach', Health Economics Review, vol. 16, no. 4, pp: 1-10.

[10] Khan, Z., Mehnaz, S., Ansari, M. A., Khalique, N. \& Siddiqui, A. R. (2009), 'Existing practices and barriers to avail of maternal healthcare services in two slums of Aligarh', Health and Population: Perspectives and Issues, vol. 32, no. 3, pp: 113-123.

[11] Nelly, V., Friel, S., Fotso, J. C., Khadr, Z., Monge, P., Deshmuk, A. P. (2011), 'Social conditions and urban health inequalities: realities, challenges and opportunities to transform the urban landscape through research and action', Journal of Urban Health, vol. 88, no. 6, pp: 1183-1193.

[12] Lee, A., Cheng, F. F., Fung, Y \& Leger, S. L. (2006), 'Can health promoting schools contribute to better health and wellbeing of young people? The Hong Kong experience', Journal of Epidemiology Community Health, vol. 60, no. 6, pp: 530-536.

[13] World Health Organization (2010), 'Regional consultation on health of the urban poor', Regional Office for South-East Asia.

[14] Blanco, I. \& Subirats, J. (2008), 'Social exclusion, area effects and metropolitan governance: a comparative analysis of five large Spanish cities', Urban Research Practice, vol. 1, no. 2, pp: $130-148$.

[15] Choudhury, N., Moran, A. C., Alam, M. A., Ahsan, K. Z. \& Rashid, S. F. (2012), 'Beliefs and practices during pregnancy and childbirth in urban slums of Dhaka, Bangladesh', BMC Public Health, vol. 12, pp: 1-6.

[16] Dollar, D. \& Gatti, R. (1999), 'Gender inequality, income and growth: are good times good for women?' The World Bank.

[17] Adams, A. M., Herfina, Y., Nabana, S. M. \& Hanifi, S. M. M. A. (2015), "Building social networks for maternal and newborn health in poor urban settlements: a cross-sectional study in Bangladesh', PLOS ONE, vol. 10, no. 4, pp: 1-17.

[18] Laverack, G. (2006), 'Improving health outcomes through community empowerment: a review of the literature', Journal of Health Population and Nutrition, vol. 24, no. 1, pp: 113-120.

[19] Wallerstein, N. (1993), 'Empowerment and health: the theory and practice of community change', Community Development Journal, vol. 28, pp: 218-217.

[20] Everson, S. A., Lynch, J. W., Chensney, M. A., Kaplan, G. A., Goldberg, D. E. \& Shade, S. B. (1997), 'Interaction of workplace demands and cardiovascular reactivity in progression of carotid atherosclerosis: population based study', Brazil Medical Journal, vol. 314, pp: 553-558.

[21] Goodman, R. M., Speers, M. A., Mcleroy, K., Fawcett, S., Kegler, M. \& Parker, E. (1998), 'Identifying and defining the dimensions of community capacity to provide a basis for measurement', Health Education Behaviour, vol. 25, pp: 258-278. 